\title{
ChemicalToolBoX and its application on the study of the drug like and purchasable space
}

\author{
Xavier Lucas*, Björn A Grüning, Stefan Günther \\ From 9th German Conference on Chemoinformatics \\ Fulda, Germany. 10-12 November 2013
}

The ever increasing amount of data and computational capabilities in the cheminformatics field has led to a scenario where efficient techniques for storage and processing in an integrated, modular, and easily accessible platform are in vital demand. Here, we present ChemicalToolBoX, a compilation of more than 30 tools integrated into a single computational chemistry and cheminformatics platform based on the Galaxy workflow management system $[1,2]$. We have recently designed a workflow within the ChemicalToolBoX to generate a library of compounds containing around 70 million unique commercially available small molecules, i.e. the purchasable space [3]. Subsequently, we have used filtering rules based on structural patterns and chemical alarms to discard problematic molecules, representing a very large portion of the drug-like and purchasable space, along with other drug discovery data sets including more than 2 million fragments (Figure 1). Furthermore, we have

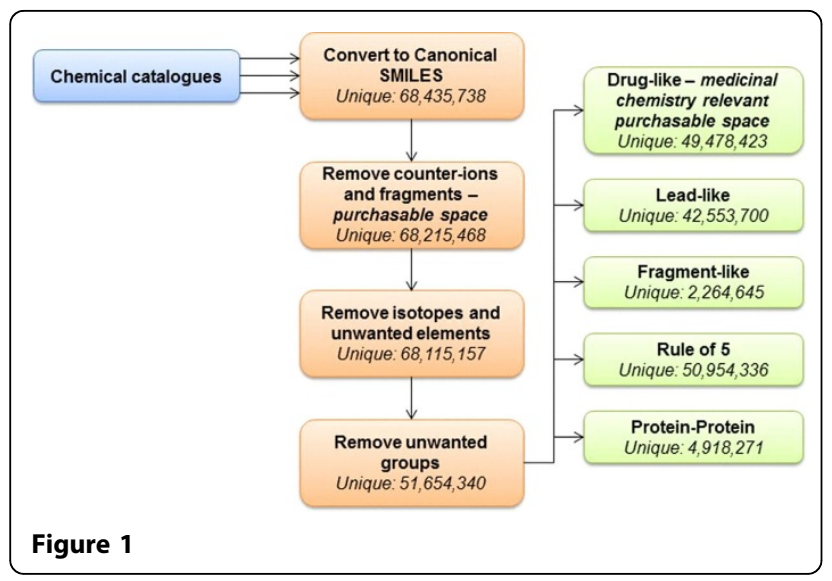

* Correspondence: xavier.lucas@pharmazie.uni-freiburg.de Pharmaceutical Bioinformatics, Institute of Pharmaceutical Sciences, AlbertLudwigs-University, Freiburg, D-79104, Germany computed several physicochemical descriptors to discover general trends applying to each subset.

Published: 11 March 2014

\section{References}

1. [https://github.com/bgruening/galaxytools/tree/master/chemicaltoolbox]

2. Grüning BA, et al:, submitted.

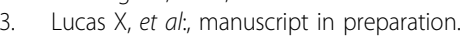

\section{doi:10.1186/1758-2946-6-S1-P51}

Cite this article as: Lucas et al:: ChemicalToolBoX and its application on

the study of the drug like and purchasable space. Journal of

Cheminformatics 2014 6(Suppl 1):P51.

\section{Publish with ChemistryCentral and every scientist can read your work free of charge \\ "Open access provides opportunities to our colleagues in other parts of the globe, by allowing anyone to view the content free of charge." \\ W. Jeffery Hurst, The Hershey Company.}

- available free of charge to the entire scientific community

- peer reviewed and published immediately upon acceptance

- cited in PubMed and archived on PubMed Central

- yours - you keep the copyright

Submit your manuscript here:

http://www.chemistrycentral.com/manuscript/

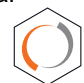

Chemistry Central 